Implementing the Single Assessment Process: Opportunities and Challenges.

Angela Dickinson

PhD MMedSci RGN BSc(Hons)

Senior Research Fellow

Centre for Research in Primary and Community Care, University of Hertfordshire,

Hatfield, England.

Address for Correspondence:

Angela Dickinson

Centre for Research in Primary and Community Care

Faculty of Health and Human Sciences

Hatfield College Lane Campus

Hatfield

Herts

AL10 9AB

UK

Email: a.m.dickinson@herts.ac.uk

Fax: 01707285995 


\section{Implementing the Single Assessment Process: Opportunities and Challenges.}

\section{Abstract}

The Single Assessment Process (SAP) has been introduced as part of the National Service Framework for Older People (DoH 2001) and has major implications for health and social care.

The aim of this study was to evaluate a pilot introduction of the Single Assessment Process in the South-East of England. A qualitative case study design incorporating observation and semi-structured interviews were used to collect data.

Assessment visits were observed and recorded, and interviews were carried out with older people and their carers $(n=9)$, health and social care practitioners, operational managers, and other key individuals involved in the pilot $(n=26)$.

Overall the evaluation found three major themes that had an impact on the implementation of the Single Assessment Process. These were: the process of implementing policy and change, the health and social care boundary, and communication and sharing of assessments. Front-line practitioners (street-level bureaucrats) had a major impact on the SAP implementation, particularly through their reluctance to engage with the process, work together and share assessments. Success of the national SAP implementation will depend on the extent to which those working directly with older people can be engaged in the policy process.

\section{Key words}

Assessment, single assessment process, policy implementation, older people 


\section{Implementing the Single Assessment Process: Opportunities and Challenges.}

\section{Introduction}

\section{SAP background/origins}

The Single Assessment Process (SAP) for older people in England was first proposed in the NHS Plan, developed in the National Service Framework for Older People (DH 2001), and detailed further by the Department for Health in 2001 (DH 2001a). The National Service Framework for Older People (NSF OP) outlines a 10-year programme that sets national standards in eight key areas in order to improve health and social care services for older people in England. The (SAP) was introduced as part of Standard Two: Person-centred care, and describes 'a single assessment process across health and social care' (DH 2001:30). The policy is an attempt to elevate standards of assessment, to facilitate information sharing between health and social care in order to improve efficiency and lead to more effective care (HSC 2002/001: LAC (2002)1 DoH 2002a), and to provide greater equality in access to multi-agency services (Wild 2002). Nine domains of assessment are required; user perspective, clinical background, disease prevention, personal care and physical well-being, senses, mental health, relationships, safety and immediate environment and resources. Intended outcomes should be agreed with the older person and specified in care plans.

Initial guidelines regarding assessment tools within the NSF OP (DoH 2001) were deliberately vague (Glasby 2004) and appeared to be based on a scant evidence base. There also appears to be an inherent contradiction within the aims of the SAP, i.e. in the requirement for assessments to be person-centred, while at the same time standardising the process. Further guidance for implementation ( $\mathrm{DoH} 2002 \mathrm{~b})$ give broad guidance rather than recommending specific tools, indicating 'home grown' tools are acceptable as long as they followed the guidance (HSC 2002/001 LAC (2002)1 DoH 2002a). 
These include directions that there should be one or more of four types of assessment in order that the scale of assessment is in proportion to need. The four types are:

- The contact assessment, which records basic information about the nature of the problem/s at the first contact with formal services;

- The overview assessment a more rounded assessment in which some of the domains outlined in the SAP are explored e.g. personal care and physical well-being;

- in-depth (specialist) assessment, exploring specific needs in detail;

- and the comprehensive assessment where specialist assessments across a range of areas are needed.

On completion of the assessment, the information collected has to be recorded in a way that enables it to be shared between health and social care professionals and organisations, which may present practical difficulties (Glasby 2004; Mouratidis et al. 2003) or a 'bureaucratic nightmare' (Grimley Evans and Tallis 2001).

Assessment has been defined as the 'means by which practitioners ascertain the needs of individuals in order to determine the most appropriate location for care and match services to need (Worth 2001:257). It is a key element and one of the core skills of the practice of health and social care practitioners (Milner 2002; Houston 2002; DoH 1990). In England the NHS and Community Care Act (DoH 1990) stated that assessment was a separate and important activity and that needs led assessment and care management should form the cornerstone of high quality care (Parry-Jones 2001). Social workers and community nurses (in particular district nurses) have been identified as the key professionals in the assessment of the health and social needs of older people (Worth 2001). 
However, assessment practice has been described as problematic (Audit Commission 1999; Social Services Inspectorate 2003; Nolan and Caldock 1996, Challis et al 2004), and previous policies that set out to improve assessment practice in community based services have proved to be unsuccessful in terms of addressing collaboration across health and social care and achieving seamless care or involving users or carers in the process. It is argued that assessment has continued to be driven by service availability rather than needs (Lewis \& Glennerster 1996; Qureshi 2002).

Improving assessment practice and procedures is not solely a policy focus in England. Scotland and Wales have developed policies for a similar process, the Single, Shared Assessment, and the Unified Assessment procedures respectively (Joint Future Group 2000, Welsh Assembly Government 2003). Furthermore the quality of assessment appears to be an issue in other countries, eg USA (Douglass 2001), the Netherlands (Algera et al 2003) and Australia (van Eyk and Baum 2002).

Current assessment practice remains subjective and context specific, but is the route to a range of services and funding. Therefore, older people are dependent on the variable skills, knowledge and judgement of the assessor for the outcomes of the assessment process, that is, provision of services (Lewis \& Glennerster 1996; Healy et al 2002). Thus the outcomes of assessment will impact on the ability of older people to continue to live at home (Davey et al 2005).

Possibly the greatest potential threat to the successful implementation of SAP will be the need for professionals from health and social care to work together. The boundaries between health and social care have been in existence at least since the modern welfare state was established (Lewis 2001). In England, the boundaries are evidenced by the division of health and social care delivery between separate organisations. Within the National Health Service in England, primary care health services are currently 
commissioned and managed within Primary Care Trusts (PCTs), while social care services are managed and provided through local councils. Current government policy places a great emphasis on partnership working (DoH 1997 and 1998). Collaborations across health and social care boundaries have been defined as 'a way of working with others on a joint project where there is a shared interest in positive outcomes' (Sullivan \& Skelcher, 2002: 1). However, inter-agency and interprofessional collaboration have proved to be difficult to achieve in practice. Reasons given for the difficulties include; differing professional perspectives, cultures and poor understanding of professional roles (Malin et al. 2002).

This division is particularly problematic for those providing services to older people whose needs frequently include both health and social care (Payne et al 2002; Manthorpe and Iliffe 2003). Partnership working is a central theme of the current UK Government's 'Third Way' policies (Hudson 2002) and aims to blur boundaries in order to provide seamless care across health and social care to patients (Hubbard and Themessl-Huber 2005). However, overcoming the barriers to joint working have been likened to demolishing the Berlin Wall (Kharicha et al 2005). It is against this backdrop that the implementation of SAP is taking place.

In summary the SAP is currently being introduced throughout the country. Despite this there is currently little evidence to support the most effective assessment approach or tools, or to support how an effective joint and single process of assessment can best be implemented. It is essential that the implementation of such a major change in the assessment of older people is evaluated and that the findings are used to inform and develop practice for health and social care professionals, both locally and nationally. It is against this background that the following evaluation explored the implementation of the SAP took place in one locality in England. 


\section{The Evaluation}

This study is an evaluation of the Single Assessment process as it was piloted in one area, geographically defined by a Primary Care Trust in the South-East of England. The evaluation aimed to produce information about the implementation, operation and effectiveness of this pilot in order to inform and guide further action (Clarke 1999), that is the extension of the process across the County.

This paper will focus on the following areas of inquiry,

- How did the local implementation of the SAP policy have an impact on the work of health and social care practitioners?

- How did the organisations manage the implementation?

- Did the SAP tools and associated documentation achieve their purpose?

The full study is reported elsewhere (Dickinson and Windle, 2003).

Evaluation research makes use of a wide range of social research methods. In this study a descriptive case study design was used to enable the impact of the SAP to be investigated within its 'real-life context' (Øvretveit 1998). Thus, all contextual factors of the pilot phase of the SAP were important and incorporated within the analysis Stake (1995). This involved older people, carers, health and social care professionals working in the community setting, and managers (at both strategic and operational levels).

The study included both exploratory and explanatory stages. The exploratory case study (Marinetto 1999; Yin 1993) enabled an overall description of the SAP pilot and drew on the major data collection methods of interviews with key players within the policy implementation and examination of, for example, the SAP steering group minutes and government documentation. 
The explanatory case study attempted to explain why and how particular findings occur (Yin 1994). Non-participant observation of the assessments enabled the researcher to see how the practitioners used the documentation and undertook assessments in the 'natural' setting. The assessment was tape recorded and the researcher took field notes. Following the assessment, the researcher undertook a short interview to capture the older person's (and informal carer's where present) perspectives of the assessment process. Semi-structured interviews were conducted with the health and social care practitioners who had been observed. Questions focused on the impact SAP was having on their work with older people, and workload, as well as the logistics of information sharing and making referrals, ease of use of the tool and other documentation used.

\section{Access to practitioners and those being assessed}

The pilot set out to be time limited, which resulted in a very small window of opportunity for recruitment and data collection (three months). A range of approaches was used to recruit participants, these included attending team meetings, letters to the individual practitioners, with follow-up emails, faxes and telephone calls. Managers were also asked to encourage staff to take part.

Practitioners, acting as gatekeepers, were asked to invite older people and their carers to participate in the study as they planned the assessment visit, thus gaining initial agreement. Verbal and written information about the project was provided and written informed consent was gained by the researcher prior to data collection.

Ethics approval for the study was gained from the Local Research Ethics Committee.

\section{Sample:}


Recruitment of front-line practitioners to the study was difficult. As the study progressed, it became clear that many practitioners had decided not to undertake the SAP overview assessments. As they were acting as gatekeepers to service-users, this had a knock on effect on access to older people and their carers. Therefore, a relatively small number of assessments were observed (seven overview assessments and tape-recordings of nine contact assessments). In total, 26 interviews were undertaken with health and social care professionals and managers, and nine service-users and carers. Professional and agency backgrounds are summarised in Table 1.

\section{Data Analysis}

The identification of themes and developing and refining categories was carried out in an inductive way following the constant comparative method of grounded theory (Glaser \& Strauss, 1967). Data analysis was managed using N5® software.

Due to the small sample size, in order to maintain anonymity, participants are identified as health care practitioners (HCP) or social care practitioners (SCP) when using excerpts from the data to illustrate the themes.

\section{Findings}

The categories and themes emerged from the data and are summarised in Figure 1 and explored and illustrated in more detail in the following sections using extracts from the data. Overall the evaluation found three major categories that had an impact on the implementation of the Single Assessment Process:

- the process of implementing policy and change,

- the health and social care boundary, and

- communication and sharing of assessments. 


\section{Implementing policy and change}

Difficulties associated with the SAP policy implementation illustrates how policy directives, which are intended to have a direct impact on the work of practitioners can be thwarted (Lipsky 1980). Successfully implementing change is a complex and non-linear process, which requires ownership, support, communication and facilitation (Bryar \& Bannigan 2003)

\section{Management and leadership}

Managers were interviewed during the evaluation to explore both their perceived roles in the SAP implementation, and the practical management issues that the SAP raised for them. Managers had interpreted their role within the implementation in two distinct ways leading to very different management styles. The first was an almost laissez fair or 'disengaged' attitude to the implementation, with little active facilitation or direction of front line practitioners, despite being aware that staff were having difficulties:

"I mean I know that they are quite negative about it out there because it's such a shift in the way they work and the culture of the two different organisations, the way they work, and they are finding it hard to take it on board..." Manager 1

However, this manager was not totally engaged with what the practitioners were actually doing in their everyday practice.

"I think they're opting out now, I think that because of the time constraints they're jumping and missing the overview, they're going from the contact to the in-depth and missing out that middle bit. (My emphasis) Manager 1

The manager acknowledged that they had failed to provide the support needed.

“...we haven't probably supported them enough in this and we have to hold our hands up to that. "Manager 1 
In contrast to the laissez faire management style, some managers actively supported front-line staff through the 'teething problems', encouraged practitioners to persevere with the process and requested their feedback on the tool and outcomes. This manager had accompanied staff on assessment visits to see at first hand the SAP in practice.

"... actually it's almost daily I'm discussing the single assessment and trying to motivate staff and help them understand... and they're focussing on it as a form [document], rather than a process that they are part of and that they can manage in a different way ... and I have done a few visits with the staff, purely and simply to say, 'right, you'll be doing the single assessment on this one and I'm going to come with you', and picked up that there are some areas of the form that they feel comfortable with and there's others they feel very uncomfortable with." Manager 2

The evaluation showed that these differences in management style had an impact on practitioners' engagement in the process. Staff who felt supported, utilised the tools and began to embed the SAP within their practice. Thus, one practitioner describes having done 'lots and lots of them [assessments]' and explains that she's 'a whiz at them now'. Those who perceived little active management support remained reluctant to engage in the SAP process throughout the pilot phase. Most of these practitioners had done very few overview assessments, some had not done any, and showed the researcher the pile of documentation in a box in their office. One practitioner described the poor management support:

"We'd not been getting that much information from our manager...Yes because even at the staff meetings, the agenda was always set and [manager] would come and say what they'd got to say about it and that was it." Practitioner 
In this pilot, the implementation followed a 'top down' approach (Lewis \& Glennerster 1996) increasing the importance of the role of operational managers in determining how the SAP was incorporated into the everyday practice of front-line practitioners.

\section{Ownership}

All the health and social care practitioners focused much of their attention and frustration on the actual assessment tools that were the tangible manifestation of the SAP. They identified issues of ownership as a major cause of disillusionment and described their lack of involvement:

"So I guess maybe we never saw it as our baby, it was always something that was basically a social services document, not our document, so I think that had some impact, maybe if it had been something we'd devised..." Health Care Practitioner (HCP)

They felt that their involvement could have had particular benefit for the development of the tool and contrasted the SAP tools with the assessment documentation they were using before the pilot that had been developed locally. This was felt particularly strongly when people had been personally involved in the development process:

“...in fact it was a collaborative work, I was involved in this, actually with this one working with the social workers and the OT and the nurses and we put our heads together and we came up with these [forms]... I mean I don't think we were shown these [SAP tools] before they were piloted." HCP

The importance of instilling a sense of ownership in order to successfully implement change in practice has been recognised in much of the change literature (e.g. Bryar \& Bannigan 2003).

\section{Role confusion}


Practitioners involved in the pilot thought that engaging in the SAP asked them to extend or change their professional role. For example, they lacked confidence and were uncertain when asking questions that they perceived to be outside their professional knowledge base:

"No I think people still find it time consuming and a waste of time, because a lot of the stuff is not things that maybe nurses need to be assessing, we're the specialists and we wouldn't expect a social worker to be going and assessing a wound, whereas we would need help with like information about benefits and I think if you're assessing that you need to have a good knowledge ... I think we need to understand where our boundaries lie and I think where our roles lie really, yes we need to know certain bits about social services and what social workers do, but I don't think we need to know it in great depth." HCP

The above practitioner may also be demonstrating professional protectionism, which Nolan \& Caldock (1996) suggest inhibits joint working practice.

There was a lack of clarity around current roles:

"... up until now they do their thing, we do our thing. I don't think there is much knowledge of what each other's roles are, I mean what do district nurses do? They don't do this and they don't do that, so what do they do? and only by working more closely with people do we find out what exactly they do. They think the same about us..." Social Care Practitioner (SCP)

There was also a fear that roles may be lost:

"Of course, the problems will come as to whose role is what, blurring our roles." SCP 
Poor understanding of the roles of other health and social care professionals has been described elsewhere (Kharicha et al 2005). However, some positive effects on practice were also identified:

"I do think I look a bit more globally on things. Asking on benefits and things like that I would not normally do, I still don't feel overly happy about asking about that because I know nothing about it... but I understand the reason of putting it in there in order to flag up any problems." HCP

Implementing the SAP will mean that practitioners have to develop new knowledge and work in different ways across traditional health and social care boundaries, which will require support.

\section{Assessment tool}

The pilot study focused on the first two stages in the SAP process, i.e. the contact and overview assessments. The tools for these assessments were developed locally and covered the domains indicated in the guidance ( $\mathrm{DoH} 2001)$. The tools were a frequent focus of staff criticisms. Due to limitations of space, discussion here will be limited to the perceived impact of the assessment tools on practice.

Practitioners were observed to use the tool in several ways, some asked every question on the form and read the questions to the service-user. Others used the tools in a more flexible way, asking some questions from the tool, but also exploring some issues in more depth in response to service users. One person did what they described as their usual assessment, completing the paperwork on return to their office, but had failed to cover some of the domains.

The lack of clear local guidance meant that practitioners had made their own decisions about how to use the tools. Some decided to only complete the overview assessment if 
they thought another professional needed to be involved, indicating a lack of understanding of the purpose of the overview assessment.

"I'm not sure when it's necessary to do a complete overview to be honest either, I don't know." HCP

Despite criticisms of the tools, some practitioners acknowledged that the information covered was relevant which had consequently broadened their assessment practice. However, without understanding the purpose of the questions, there is a danger that information is collected without interpretation of its relevance or importance:

“...I do answer every question even though I know nothing about some of the questions, you just put in something." SCP

The SAP tool asks practitioners to explore issues from the perspective of the older person which caused difficulties for some who preferred to focus on, for example, the medical diagnosis:

"Okay if I faxed this through ... or if they faxed it through to me, it doesn't tell me a thing, it doesn't tell me what's wrong with the patient. All it tells me is what the patient is concerned about but it's not the actual thing that needs doing. It's just hopeless I think." HCP

However, the NSF OP (DoH 2001) is clear that the starting point of assessment should be the service user.

\section{Education and training}

Practitioners commented on the poor preparation and training they had received prior to the start of the pilot, and lack of opportunity to become familiar with the tools:

"No, I think it got off on a very wrong foot. We should have learned a lot more about the form, a lot more about what was expected of us." SCP 
All felt unprepared for using the new assessment tools. They had not seen the final versions of the tools until they began using them. One person noted that 'it was crazy how it happened, it came out Friday night, we had to start Monday, so it got off to a very bad start, people hated it from the word go'. The training sessions were reported as being a maximum of two, two-hour sessions. Clearly, successful integration of SAP will require educational input as well as training in the use of the assessment tools.

\section{Health and social care boundary}

It is probably no surprise that the division between health and social care was found to have had an impact on the implementation. However, the way in which this has had an impact deserves some discussion.

\section{Trusting assessments of others}

For the SAP to work, particularly in the reduction of assessment burden for older people through eliminating duplication, health and social care practitioners need to feel confident with, and trust each other's assessments. However, when discussing sharing assessment information, practitioners tended to lack confidence in the assessments undertaken by other professionals:

“...we have to assess ourselves rather than depending on somebody else's assessment and l'd rather do my own assessments actually rather than picking up somebody else's and just going blindly. You still need to assess..." HCP

However, within the general feeling of mistrust, examples were found where this had been overcome:

“...I think it is difficult initially to trust, always trust other people's assessment I suppose. [Professional] I didn't have a problem with but I suppose ... it's difficult to trust always, but we've got to learn haven't we?" HCP 
Further probing to explore the reasons for trusting this particular person's assessment, revealed that trust was more difficult when there was no prior working relationship, that is, 'if you haven't actually seen them in practice'. The assessment was less likely to be questioned if someone was commenting on issues within their own practice domain, rather than her own, again indicating professional protectionism:

"If the nurse was talking about continence and medication things I would trust what they were saying, but on mobility issues I wouldn't not believe them but I would probably still feel better assessing it and doing it myself." HCP

Additionally, due to the logistical issues around information sharing, only one of the professionals interviewed had actually seen or shared an overview assessment conducted by someone from another organisation.

Therefore, the evaluation found that there were major issues around trust and professional protectionism that need to be addressed. Worth (1998) also identified suspicion between health and social care practitioners about the standard of each other's assessments. However, the practitioner quoted above does indicate a possible way forward through provision of opportunities for closer working relationships.

\section{SAP: Improving working relationships between organisations?}

The data showed a commitment at all levels of health and social care for closer working. There were good working relationships at managerial and strategic levels of the organisation and both joint management meetings and joint appointments were evident. However, these positive experiences had not filtered down to front-line practitioners.

"I think managers do speak, do talk between health and social services. It's not too bad maybe at higher levels, but the workers have no time and no opportunity either unless we're having to be working jointly." SCP 
Implementing the SAP drew attention to the unresolved organisational barriers as one manager explained:

"I actually asked a member of staff to phone them up and say "can I have a copy of your single assessment, so I can have an overview of your assessment"? So the comments I'm getting back are "it's in the client's house, so if you want to see it go and look at it". Or, I actually got a copy sent through and they're not doing the overview assessment, they're doing the contact assessment. So it's causing resentment rather than getting people working together." Manager

Local general practitioners had also been invited to participate in the SAP, but were reported to be difficult to engage.

“The GPs, you can't get them involved with anything. We had I think ...four originally that we were working with and slowly, slowly, they dropped off ...I mean, you've got to see it from their point of view - they are overworked and they are very busy." Member of implementation team

Improving cross-boundary working will be essential to the successful implementation of SAP.

\section{Logistics of information sharing}

The SAP pilot study used paper-based assessment tools, which made sharing the information between organisations problematic. In order to share the assessment information, practitioners had to first photocopy the overview assessment and then send by fax. Practitioners also described other difficulties, for example, they found it difficult to know if an overview assessment had already been done: 
"And they want you to fax through all these, faxing through 21 pages, it is very time consuming. That means we've got to come back, stand at the photocopier, photocopy it and then you fax it through. We haven't got the time...it is a waste of resources." HCP

Using electronic versions of assessment tools to improve storage and share information about service-users easily and confidentially is crucial if the SAP is to function as intended.

\section{Discussion}

The findings presented here suggest that despite over a decade of work aimed at improving the assessment practice of health and social care professionals, many challenges remain. The data presented here outline the major challenges and opportunities, both for those charged with implementing this policy, and practitioners seeking to utilise the SAP. Although this study gathered data from a small pilot study, the findings resonate with the academic literature that has emerged since the introduction of the NHS and Community Care Act (DH 1990). Information technology may provide some improvements to the ability to share information. However, currently there is a great deal of fragmentation and incompatibility of systems both within and between organisations, and it is clear that this is only one of a number of issues to be solved. Unwillingness to share assessments has been found elsewhere (e.g. Kharicha et al 2005).

Joint working presents a number of difficulties (Lewis 2001), some of which have been presented earlier. However, successful implementation of SAP will require health and social care professionals to learn and engage with new ways of working together. While staff acknowledged that there could be advantages to working more closely together, 
they indicated, often through refusing to engage with the SAP implementation, their unwillingness to make changes to working practices. Kharicha et al (2005:404) in a study of GPs' and social workers' perspectives on joint working, found that 'each profession wanted the other to change its way of working'. New ways of working together will only happen when professionals have opportunities to actually work together which may require 're-socialisation' (Hubbard and Themessl-Huber 2005:382).

Top-down approaches to policy implementation are frequently criticised as they neglect to address the impact of front-line staff on the process (Hudson 2002). Lipsky (1980) describes the front line staff who interact directly with the public, act as 'gate-keepers' to government services and draw on social and contextual resources to resolve the situations they face, as 'street-level bureaucrats'. Street-level bureaucrats have to make decisions about how limited resources such as services are allocated, and in the case of SAP have to use discretion in how they apply the assessment policy. The lack of clarity in the guidance about the detail of the SAP, both from the government and locally, from management, left front-line staff to use their own judgement to interpret the SAP. Staff were also asked to implement a policy, which they felt they had been poorly informed and consulted about. They felt that the consequences to them in terms of increased workload had not been considered, leading to feelings of resentment and frustration. Overall street-level staff have to deal with the stress and complexity of their everyday work, thus, they make decisions on implementing policy in a way which is acceptable and preserves control over workload and roles. In this case, frequently, the decision was to continue to work as they had done before, a choice which was implicitly supported by management through their failure to challenge or support staff. Exploration of the views and experiences of street-level staff, enables an understanding of how 
failing to address their concerns could have potentially dire consequences for the national SAP implementation.

Findings from this study were fed back in a number of ways to those leading the implementation at a strategic level, managers and practitioners. This resulted in the implementation of a number of strategies for the roll out of the SAP, i.e. establishment of Local Implementation Teams in each locality across the county and initiation of joint education and training (Casson and Skidmore 2005).

This study reports on a pilot implementation in only one area, and was further limited by its relatively small sample due to the time frame of the pilot and the poor involvement of front-line practitioners with SAP. However, the most recently available figures found that a quarter of councils had made little progress towards SAP implementation with only six per cent reporting a fully operational process across health and social services, as well as poor involvement by GPs and hospitals (SSI 2003). This indicates that others may also be experiencing difficulties with the implementation. A national evaluation of the implementation and impact of SAP is underway (Challis et al 2004) and is due to report in October 2006. Further work is required to explore the impact of SAP on outcomes for service users and carers as well as in more diverse populations. The effect that improving joint working will have on outcomes for older people and their informal carers also requires study (Hubbard and Themessl-Huber 2005).

\section{Conclusion}

In order to close the implementation gap for SAP, that is, to reduce the distance between policy objectives and achievements, practitioners working in increasingly pressurised NHS and community care settings need effective support in order to change the way they practice. Practitioners cannot be expected to make this transition unaided and 
without this support, are likely to respond by limited or non-participation in the process as seen in this evaluation and previous work:

'The pivotal role given to assessment meant success or otherwise of the reforms lay in part on the ability of practitioners to make this transition.' (Parry Jones \& Soulsby 2001)

This study highlights the need to engage street-level bureaucrats in the policy process using the mechanisms of effective management, further education and training, work to enhance collaboration and cross disciplinary working. Ensuring that the appropriate infrastructure is in place will also ease further progress in the implementation of SAP. 


\section{References:}

AUDIT COMMISSION. (1999). First Assessment: A review of district nursing services in England and Wales. Audit Commission: London.

BRYAR, R. \& BANNIGAN, K. (2003). The process of change: issues for practice development. In: BRYAR, R.M. AND GRIFFITHS, J.M. (Eds) Practice development in community nursing: principles and processes. London: Arnold.

CASSON, S. and SKIDMORE, D. (2005) Single Assessment Process in Hertfordshire: Investing in Change Management. Journal of Integrated Care. 13(2), 28-33.

CHALLIS D, CLARKSON P, HUGHES J, ABENDSTERN M, SUTCLIFFE C AND BURNS A (2004). A systematic evaluation of the development and impact of the SAP in England. Manchester: PSSRU. http://www.pssru.ac.uk/pdf/p060.pdf (accessed 27.02.06).

CHALLIS, D. CLARKSON, P. HUGHES, J. ABENDSTERN, M. SUTCLIFFE, C. \& BURNS, A (2004). A systematic evaluation of the development and impact of the Single Assessment Process in England. Manchester:PSSRU. http://www.pssru.ac.uk/pdf/p060.pdf (Accessed 27.02.06).

CLARKE, A. (1999). Evaluation Research. London: Sage.

DAVEY, B., LEVIN, E., ILIFFE, S. \& KHARICHA, K. (2005). Integrating health and social care: implications for joint working and community care outcomes for older people.

Journal of Interprofessional Care. 19 (1), 22-34.

DEPARTMENT OF HEALTH. (1990). The National Health Service and Community Care Act. London, HMSO.

DEPARTMENT OF HEALTH. (1997). The New NHS, Modern, Dependable. London: The Stationary Office. 
DEPARTMENT OF HEALTH. (1998). Modernising Social Services: Promoting Independence, Improving Protection, Raising Standards. London: HMSO.

DEPARTMENT OF HEALTH. (2001). National Service Framework for Older People. London: The Stationary Office.

DEPARTMENT OF HEALTH. (2001). The NHS Plan: A plan for investment, a plan for reform. London: The Stationary Office.

DEPARTMENT OF HEALTH. (2002a). HSC 2002/001: LAC (2002)1. Guidance on the single assessment process for older people. London: Department of Health.

DEPARTMENT OF HEALTH. (2002b). The single assessment process: Assessment tools and scales. London: Department of Health.

DICKINSON, A. AND WINDLE, K. (2003) Evaluation of the Single Assessment Process Pilot Phase in Hertsmere. Hertfordshire: University of Hertfordshire.

GLASBY, J. (2004). Social services and the Single Assessment Process: early warning signs? Journal of Interprofessional Care. 18 (2), 129-139.

GLASER, B. \& STRAUSS, A. (1967). The discovery of grounded theory. Chicago: Aldine.

HAMMERSLEY, M. \& ATKINSON, P. (1995). Ethnography: Principles in practice ( $\left.2^{\text {nd }} E d n\right)$ Routledge: London.

HOUSTON, A.M. \& COWLEY, S. (2002). An empowerment approach to needs assessment in health visiting. Journal of Clinical Nursing. 11, 640-650.

HUBBARD, G. \& THEMESSL-HUBER, M. (2005) Professional perceptions of joint working in primary care and social care services for older people in Scotland. Journal of Interprofessional Care. 19(4), 371-385. 
HUDSON, B. (2002) Interprofessionality in health and social care: the Achilles' heel of partnership? Journal of Interprofessional Care. 16(1), 7-17.

JOINT FUTURE GROUP. (2000). Community care: a joint future. Edinburgh: Scottish Executive.

KENNEDY, C.M. (2002). The work of district nurses: first assessment visits. Journal of Advanced Nursing. 40 (6), 710-720.

KHARICHA, K. ILLIFFE, S. LEVIN, E. DAVEY, B. \& FLEMING, C. (2005) Tearing down the Berlin Wall: social workers' perspectives on joint working with general practice. Family Practice. 22:399-405.

LIPSKY, M (1980). Street-level bureaucracy: Dilemmas of the individual in public services. New York:Russell Sage Foundation.

MALIN, N., WILMOT, S. \& MANTHORPE, J. (2002). Key concepts and debates in health and social policy. Buckingham: Open University Press.

MANTHORPE, J. \& ILIFFE, S. (2003). Professional predictions: June Huntington's perspectives on joint working, 20 years on. Journal of Interprofessional Care. 17(1), 8594.

MARINETTO, M. (1999). Studies of the Policy Process: A case analysis. Prentice Hall: Europe: London

MILNER, J. \& O'BYRNE, P. (2002). Assessment in social work (2 ${ }^{\text {nd }}$ Edition). Houndmills: MacMillan.

MOURATIDIS, H., MANSON, G. \& PHILP, I. (2003). A novel agent-based system to support the single assessment process of older people. Health Informatics Journal. 9 (3), 149-162. 
NOLAN, M. \& CALDOCK, K. (1996). Assessment: Identifying the barriers to good practice. Health and Social Care in the Community. 4, 77-85.

OVRETVEIT, J. (1998). Evaluating Health Interventions. Buckingham: Open University Press.

PARRY-JONES, B. \& SOULSBY, J. (2001). Needs-led assessment: the challenges and the reality. Health and Social Care in the Community. 9(6), 414-428.

PAYNE, S. KERR, C. HAWKER, S. HARDEY, M. \& POWELL, J. (2002). The communication of information about older people between health and social care practitioners. Age and Ageing. 31, 107-117.

QURESHI H (2002) Social and political influences on services for older people in the United Kingdom in the late $20^{\text {th }}$ Century. Journal of Gerontology. 57A (11), M705-711. SOCIAL SERVICES INSPECTORATE (2003) Improving Older People's Services-An overview of performance. London: Department of Health.

STAKE, R.E. (1995). The art of case study research. Thousand Oaks: Sage.

SULLIVAN, H. \& SKELCHER, C. (2002). Working across boundaries: Collaboration in public services. Houndmills, Palgrave.

VERNON, S., ROSS, F. \& GOULD, M.A. (2000). Assessment of older people: politics and practice in primary care. Journal of Advanced Nursing. 31 (2), 282-297.

WELSH ASSEMBLY GOVERNMENT. (2003). The strategy for older people in Wales. Cardiff: Welsh Assembly Government.

WILD, D. (2002). The single assessment process. Primary Health Care. 12 (1), 20-21. 
WORTH, A. (1998). Community care assessment of older people: identifying the contribution of community nurses and social workers. Health and Social Care in the Community. 6 (5), 382-386.

WORTH, A. (2001). Assessment of the needs of older people by district nurses and social workers: a changing culture. Journal of Interprofessional Care. 15 (3), 257-266.

YIN, R.K. (1993). Applications of Case Study Research. Sage Publications: London

YIN, R.K. (1994). Case Study Research: Design and Methods. Second Edition: London 


\section{Acknowledgements:}

The evaluation was commissioned by a Social Services Department and partially funded by them. Additional funding was awarded by the Hertfordshire Primary Care Research Network (HertNet).

The author would also like to thank Dr Karen Windle and Professor Robyn Martin for comments on an earlier draft of this paper as well as the two anonymous reviewers who provided helpful and constructive comments. 
Table 1: Professional backgrounds of those observed undertaking assessments and interviewed about SAP.

\begin{tabular}{|l|l|l|}
\hline Profession/Agency & $\begin{array}{l}\text { Observation of } \\
\text { assessment }\end{array}$ & Total Interviewed \\
\hline Social Work & 2 & 10 \\
\hline Nursing & 3 & 5 \\
\hline $\begin{array}{l}\text { Allied Health } \\
\text { Professionals }\end{array}$ & 2 & 4 \\
\hline $\begin{array}{l}\text { Call Centre (Contact } \\
\text { assessments/social } \\
\text { care) }\end{array}$ & 7 & 7 \\
\hline Service-users/carers & 7 & \\
\hline Totals & $\mathbf{7}$ & $\mathbf{3 5}$ \\
\hline
\end{tabular}


Figure 1: Diagram to illustrate the major factors having an impact on the implementation of SAP.
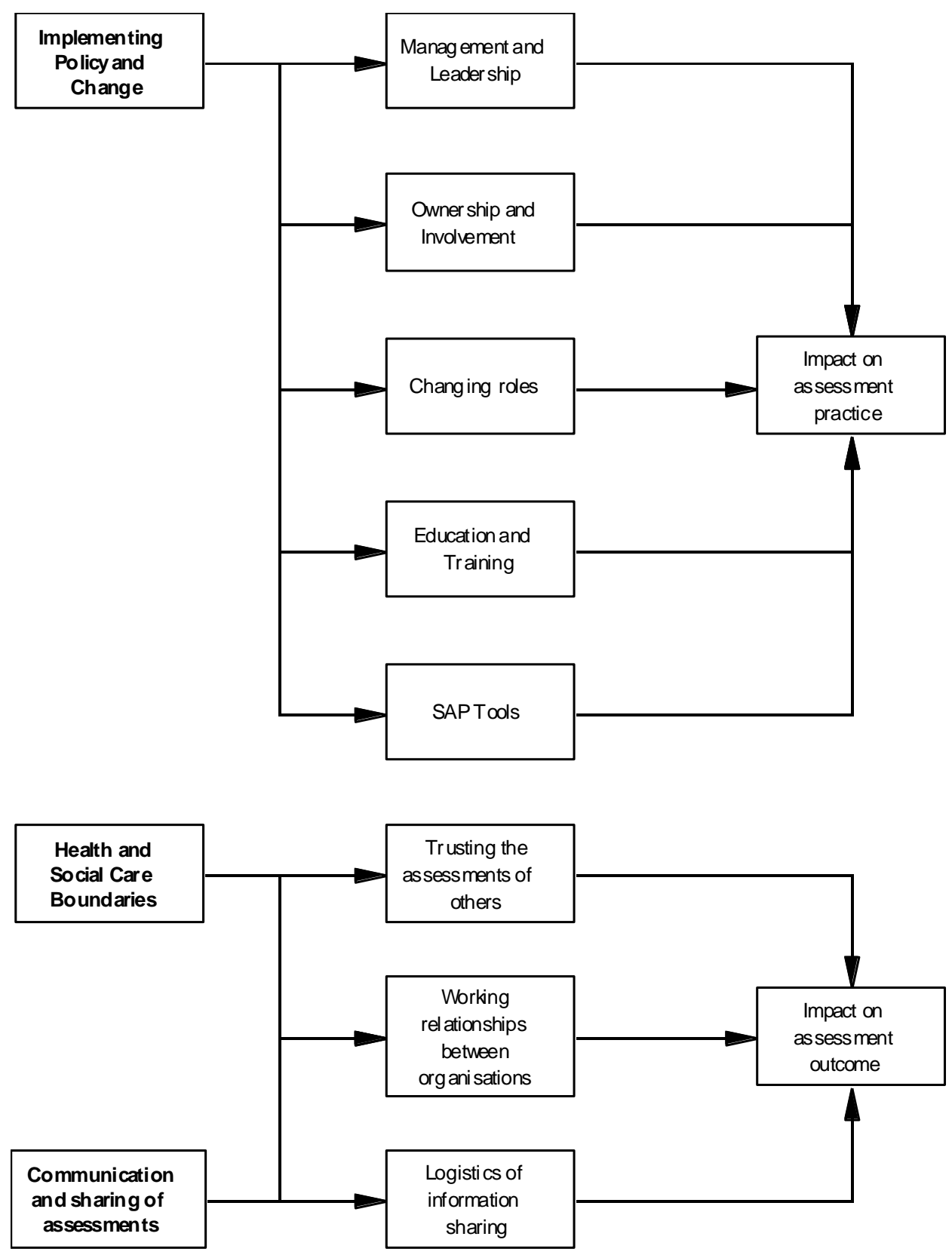